Tohoku J. Exp. Med., 2004, 203, 37-45

\title{
Reliability and Validity of the Multidimensional Health Locus of Control Scale in Japan: Relationship with Demographic Factors and Health-Related Behavior
}

\author{
Aya Kuwahara,,${ }^{1,2}$ Yoshikazu Nishino, ${ }^{2}$ Takayoshi Ohkubo, ${ }^{2}$ Ichiro Tsuji, ${ }^{2}$ \\ Shigeru Hisamichi ${ }^{2}$ and Toru Hosokawa ${ }^{3}$ \\ ${ }^{1}$ Department of Life Style Studies, Shuko Junior College, Ichinoseki 021-0902, \\ ${ }^{2}$ Division of Public Health, Tohoku University School of Medicine, Sendai \\ 980-8575, and \\ ${ }^{3}$ Department of Applied Human Development, Faculty of Education, Tohoku \\ University, Sendai 980-8576
}

\begin{abstract}
Kuwahara, A., Nishino, Y., Ohrubo, T., Tsuji, I., Hisamichi, S. and Hosokawa, T. Reliability and Validity of the Multidimensional Health Locus of Control Scale in Japan: Relationship with Demographic Factors and Health-Related Behavior. Tohoku J. Exp. Med., 2004, 203 (1), 37-45 — We assessed the reliability and validity of the Multidimensional Health Locus of Control Scale (MHLC scale) in a rural Japanese community. The study subjects were 2388 men and 2454 women aged 40-79 years, who completed a questionnaire regarding socio-demographics, healthrelated behavior, such as smoking and drinking, and the MHLC. The Cronbach $\alpha$ of the MHLC scale, which is an indicator of the internal consistency of the scale, was within the range 0.62-0.76. Elderly subjects, women, and subjects with fewer years of education showed more "external" belief, which is generally consistent with previous reports from overseas. Subjects with adverse health behavior, such as smoking and excess drinking, also had more "external" belief. These results indicate that the MHLC scale has sufficient reliability and validity among the Japanese population. Use of the MHLC scale should help to provide a better understanding of health belief among Japanese, and development of health education programs to prevent lifestylerelated disease. - health locus of control; health behavior; validity; reliability (C) 2004 Tohoku University Medical Press
\end{abstract}

Received January 10, 2003; revision accepted for publication March 23, 2004.

Address for reprints: Kuwahara Aya, Department of Food and Nutritional Science, Shuko Junior College, 49-1, Ichinoseki 021-0902, Japan.

e-mail: ayaken@cat-v.ne.jp 
It is widely accepted that health-related behavior such as smoking is largely determined by social or psychological factors, including the health belief of the individual (Pitts 1991). Thus, understanding the health belief of a target population is a prerequisite for effective health education.

Health Locus of Control (HLC) is one of the most widely measured parameters of health belief for the planning of health education programs. HLC is defined as the perception of what controls one's own health (Wallston and Wallston 1982; Wallston 1989). Various HLC scales have been developed targeting the general population or specific groups such as athletes or children (Parcel and Mayer 1978; Murphy et al. 1999).

The Multidimensional Health Locus of Control (MHLC) scale, developed by Wallston and Wallston (1978), contains three subscales: Internal HLC (IHLC), Powerful others HLC (PHLC), and Chance HLC (CHLC). Each subscale measures an individual's tendency to believe that health outcomes are due mainly to one's own behavior (IHLC), or to powerful others such as medical professionals or family (PHLC), or to chance (CHLC). PHLC and/or CHLC are classified as "external" belief, and IHLC as "internal" belief (Wallston and Wallston 1978). In Western countries, the relationships between MHLC score and socio-demographics and various types of health-related behavior such as smoking, drinking, or exercise have been investigated (Slenker et al. 1985; Calnan 1989; Fleming and Barry 1991; Schank and Lawrence 1993; Stuart et al. 1994; Bennett et al. 1997; Paxton and Sculthorpe 1999). Most of the previous studies agreed that people with low socioeconomic status (low income, fewer years of education) or adverse health-related behavior (such as smoking or excess drinking) tend to have higher "external" scores, while people with high socioeconomic status or beneficial health behavior such as regular exercise tend to have higher "internal" scores.

In Japan, Horige developed the Japanese Health Locus of Control (JHLC) scale, which is
Japanese-specific HLC scale (Horige 1991). While a Japanese-specific scale is useful for investigating the health belief of Japanese subjects, comparison of Japanese health belief data with Western data using a common scale such as the MHLC is also indispensable in order to grasp any features that are characteristics of Japanese subjects. Such an approach would provide insight into the health belief of the Japanese population, so that we could choose or modify a number of health education programs, that were originally designed for Western populations. Despite its importance, the reliability and validity of the MHLC scale for Japanese adults have not yet been verified. The purpose of this study was to assess the reliability and validity of the MHLC scale in a community setting in rural Japan.

\section{Subjects ANd Methods}

The subjects of the present study were beneficiaries of National Health Insurance, aged 40-79 years at the baseline survey in 1994, living in either Kogota or Sanbongi two towns in Miyagi Prefecture, Japan (Tsuji et al. 1998). The study area is rural and the main industry is agriculture. We conducted a baseline questionnaire survey of demographic characteristics, physical function and health behavior. Public health officials in each town visited each subject at his/her residence to deliver a baseline questionnaire and a MHLC questionnaire and to explain the objectives of the survey. The subjects were informed of their right to decline, then asked to complete the questionnaires if they agreed. Out of 6419 eligible subjects, 4842 people $(75 \% ; 2338$ men and 2454 women) completed the MHLC questionnaire.

We used MHLC Form A, developed by Wallston and Wallston in 1978, translated into Japanese by Hosokawa (see Appendix).

The MHLC, which is a six-point Likert scale, contains eighteen questions classified into three subscales: Internal HLC, Powerful-others HLC, and Chance HLC. Each subscale contains six questions. For each question, subjects chose one out of six answers ranging from "strongly 


\section{APPENDIX}

\section{MHLC Form A}

1. If I get sick, it is my own behavior which determines how soon I get well again.

2. No matter what I do, if I am going to get sick, I will get sick.

3. Having regular contact with my physician is the best way for me to avoid illness.

4. Most things that affect my health happen to me by accident.

5. Whenever I don't feel well, I should consult a medically trained professional.

6. I am in control of my health.

7. My family has a lot to do with my becoming sick or staying healthy.

8. When I get sick I am to blame.

9. Luck plays a big part in determining how soon I will recover from an illness.

10. Health professionals control my health.

11. My good heatlh is largely a matter of good fortune.

12. The main thing which affects my health is what I myself do.

13. If I take care of myself, I can avoid illness.

14. When I recover from an illness, it's usually because other people

(for example, doctors, nurses, family, friends) have been taking good care of me.

15. No matter what I do, I'm likely to get sick.

16. If it's meant to be, I will stay healthy.

17. If I take the right actions, I can stay healthy.

18. Regarding my health, I can only do what my doctor tells me to do.

agree" to "strongly disagree" (Wallston and Wallston 1978).

The Cronbach $\alpha$ was calculated to assess the internal consistency as reliability (SAS PROC FREQ) (SAS Institute 1992). We analyzed the association between MHLC score and demographic factors such as gender, age group, occupational background, and educational background. We also examined the association between MHLC scores and health-related behavior or health status: smoking, drinking, exercise habits, and body mass index (BMI) (ANCOVA, SAS PROC
GLM). For BMI, we classified the subjects into three groups: $\mathrm{BMI}<18.5 \mathrm{~kg} / \mathrm{m}^{2}, 18.5-25 \mathrm{~kg} / \mathrm{m}^{2}$, and $\geqq 25 \mathrm{~kg} / \mathrm{m}^{2}$. In order to compare the present results with previous reports from Western countries, we limited the analysis to health-related behavior for those subjects aged less than 70 years.

\section{Results}

The characteristics of the subjects are shown in Table 1. Of the 4842 study subjects, $39.9 \%$ of men and $40.0 \%$ of women were aged 60-69 years. Regarding job history, $37.9 \%$ of men were office 
TABLE 1. Characteristics of subjects

\begin{tabular}{|c|c|c|c|c|}
\hline Age group & Men & $(\%)$ & Women & $(\%)$ \\
\hline $40-49$ & 491 & $(20.6)$ & 404 & (16.4) \\
\hline $50-59$ & 485 & $(20.3)$ & 596 & $(24.3)$ \\
\hline $60-69$ & 952 & (39.9) & 981 & $(40.0)$ \\
\hline $70-79$ & 460 & $(19.2)$ & 473 & (19.3) \\
\hline Total & 2388 & $(100)$ & 2454 & $(100)$ \\
\hline Occupational background & Men & $(\%)$ & Women & $(\%)$ \\
\hline Office workers & 906 & $(37.9)$ & 600 & $(24.5)$ \\
\hline Farmers & 842 & $(35.3)$ & 818 & (33.3) \\
\hline Self employed & 527 & $(22.1)$ & 365 & (14.9) \\
\hline Retired or house wives & 113 & $(4.7)$ & 671 & (27.3) \\
\hline Total & 2388 & $(100)$ & 2454 & $(100)$ \\
\hline Educational background & Men & $(\%)$ & Women & $(\%)$ \\
\hline \multicolumn{5}{|l|}{ Graduated } \\
\hline Junior high school & 1339 & $(57.5)$ & 1225 & (51.8) \\
\hline High school & 783 & (33.7) & 886 & $(37.4)$ \\
\hline Junior college & 108 & $(4.6)$ & 239 & (10.1) \\
\hline University & 97 & $(4.2)$ & 17 & $(0.7)$ \\
\hline Total & 2327 & $(100)$ & 2367 & $(100)$ \\
\hline Drinking status & Men & $(\%)$ & Women & $(\%)$ \\
\hline Current drinker & 1688 & $(71.9)$ & 466 & $(22.3)$ \\
\hline Ex-drinker & 288 & $(12.2)$ & 108 & (5.1) \\
\hline Never & 373 & $(15.9)$ & 1518 & $(72.6)$ \\
\hline Total & 2349 & $(100)$ & 2092 & $(100)$ \\
\hline Smoking status & Men & $(\%)$ & Women & $(\%)$ \\
\hline Current smoker & 1215 & $(53.1)$ & 179 & (8.9) \\
\hline Ex-smoker & 676 & $(29.6)$ & 68 & (3.4) \\
\hline Never & 396 & $(17.3)$ & 1761 & $(87.7)$ \\
\hline Total & 2287 & $(100)$ & 2008 & (100) \\
\hline Body Mass Index & $\operatorname{Men}^{1}$ & $(\%)$ & Women $^{1}$ & $(\%)$ \\
\hline$>25 \mathrm{~kg} / \mathrm{m}^{2}$ & 260 & $(13.5)$ & 368 & $(15.6)$ \\
\hline $18.5 \mathrm{~kg} / \mathrm{m}^{2}-25 \mathrm{~kg} / \mathrm{m}^{2}$ & 1598 & $(82.9)$ & 1540 & $(77.7)$ \\
\hline$\leqq 18.5 \mathrm{~kg} / \mathrm{m}^{2}$ & 70 & (3.6) & 73 & $(3.7)$ \\
\hline Total & 1928 & $(100)$ & 1981 & $(100)$ \\
\hline Exercise habits/week & $\mathrm{Men}^{2}$ & $(\%)$ & Women $^{2}$ & $(\%)$ \\
\hline$\geqq 5$ hours & 58 & (6.3) & 34 & (5.6) \\
\hline 3-4 hours & 59 & (6.5) & 55 & (9) \\
\hline 1-2 hours & 154 & $(16.8)$ & 113 & (18.6) \\
\hline No exercise & 643 & (70.4) & 407 & (66.8) \\
\hline Total & 914 & (100) & 609 & (100) \\
\hline
\end{tabular}

${ }^{1}$ age under $70 ;{ }^{2}$ age under 70 and able to do vigorous exercize. 
TABLE 2. The association between MHLC score and age group

\begin{tabular}{|c|c|c|c|c|c|c|}
\hline \multirow{2}{*}{ Age group } & \multicolumn{2}{|c|}{$\begin{array}{c}\text { IHLC } \\
\text { (Internal) }\end{array}$} & \multicolumn{2}{|c|}{$\begin{array}{c}\text { PHLC } \\
\text { (Powerful others) }\end{array}$} & \multicolumn{2}{|c|}{$\begin{array}{c}\text { CHLC } \\
\text { (Chance) }\end{array}$} \\
\hline & Mean \pm S.E. & $p$ & Mean \pm S.E. & $p$ & Mean \pm S.E. & $p$ \\
\hline \multicolumn{7}{|l|}{ Men } \\
\hline $40-49$ & $25.59 \pm 0.186$ & & $22.53 \pm 0.183$ & & $19.41 \pm 0.243$ & \\
\hline \multirow[t]{2}{*}{$50-59$} & $25.62 \pm 0.187$ & & $22.96 \pm 0.184$ & & $19.77 \pm 0.245$ & \\
\hline & & $\mathrm{a}$ & & $\mathrm{a}$ & & $\mathrm{a}$ \\
\hline $60-69$ & $26.60 \pm 0.133$ & & $24.73 \pm 0.131 \mathrm{a}$ & & $20.45 \pm 0.175$ & \\
\hline $70-79$ & $27.41 \pm 0.192$ & & $26.22 \pm 0.189$ & & $21.03 \pm 0.251$ & \\
\hline Age group & Mean \pm S.E. & $p$ & Mean \pm S.E. & $p$ & Mean \pm S.E. & $p$ \\
\hline \multicolumn{7}{|l|}{ Women } \\
\hline $40-49$ & $25.03 \pm 0.205$ & & $22.34 \pm 0.202$ & & $20.13 \pm 0.265$ & \\
\hline \multirow[t]{2}{*}{$50-59$} & $25.67 \pm 0.169$ & & $23.72 \pm 0.166$ & & $21.20 \pm 0.218$ & \\
\hline & & $\mathrm{a}$ & & $\mathrm{a}$ & & $\mathrm{a}$ \\
\hline $60-69$ & $26.53 \pm 0.132$ & & $25.29 \pm 0.130$ & & $21.47 \pm 0.170$ & \\
\hline $70-79$ & $26.87 \pm 0.190$ & & $26.30 \pm 0.187$ & & $22.59 \pm 0.245$ & \\
\hline
\end{tabular}

${ }^{\mathrm{a}} p<0.001$. Results of analysis of variance.

TABLE 3. MHLC score by gender, occupational background, and educational background

\begin{tabular}{lccc}
\hline & Mean \pm S.E. & Mean \pm S.E. & Mean \pm s.E. \\
\cline { 2 - 4 } & $\begin{array}{c}\text { IHLC } \\
\text { (Internal) }\end{array}$ & $\begin{array}{c}\text { PHLC } \\
\text { (Powerful others) }\end{array}$ & $\begin{array}{c}\text { CHLC } \\
\text { (Chance) }\end{array}$ \\
\hline Gender $^{1}$ & & & \\
Men & $26.29 \pm 0.086$ & $24.09 \pm 0.085$ & $20.19 \pm 0.112$ \\
Women & $26.06 \pm 0.086$ & $24.46 \pm 0.084^{\mathrm{a}}$ & $21.35 \pm 0.111^{\mathrm{a}}$ \\
\hline Occupational background $^{2}$ & & & \\
$\quad$ Office workers & $26.17 \pm 0.164$ & $23.99 \pm 0.159$ & $19.71 \pm 0.205$ \\
Farmers & $26.21 \pm 0.178$ & $24.02 \pm 0.171$ & $20.77 \pm 0.222^{\mathrm{b}}$ \\
Self-employed & $26.26 \pm 0.191$ & $24.13 \pm 0.185$ & $20.64 \pm 0.239^{\mathrm{b}}$ \\
Retired/house wives & $25.80 \pm 0.211$ & $23.99 \pm 0.204$ & $20.17 \pm 0.264$ \\
\hline Educational background & & & \\
$\quad$ Junior high school & & $24.92 \pm 0.111^{\mathrm{c}}$ & $21.64 \pm 0.144^{\mathrm{c}}$ \\
High school & $26.16 \pm 0.115$ & $23.94 \pm 0.126$ & $19.98 \pm 0.163$ \\
Junior college & $26.04 \pm 0.130$ & $23.87 \pm 0.238$ & $19.86 \pm 0.307$ \\
$\quad$ University & $26.02 \pm 0.246$ & $23.40 \pm 0.394$ & $19.81 \pm 0.510$ \\
\hline
\end{tabular}

1 adjusted for age.

${ }^{2}$ adjusted for gender and age group.

${ }^{\mathrm{a}} p<0.001$ vs. Men, ${ }^{\mathrm{b}} p<0.001$ vs.office workers, ${ }^{\mathrm{c}} p<0.001$ vs. other groups. 
TABLE 4. The association between MHLC score and drinking/smoking status

\begin{tabular}{lccc}
\hline & \multicolumn{3}{c}{ Mean \pm s.E. } \\
\cline { 2 - 4 } & $\begin{array}{c}\text { IHLC } \\
\text { (Internal) }\end{array}$ & $\begin{array}{c}\text { PHLC } \\
\text { (Powerful others) }\end{array}$ & $\begin{array}{c}\text { CHLC } \\
\text { (Chance) }\end{array}$ \\
\hline Drinking & & & \\
$\quad$ Current drinkers & $26.16 \pm 0.154$ & $23.59 \pm 0.149$ & $19.78 \pm 0.193$ \\
Ex-drinkers & $26.17 \pm 0.244$ & $24.60 \pm 0.236^{1}$ & $20.97 \pm 0.306^{1}$ \\
Never & $26.01 \pm 0.162$ & $23.92 \pm 0.157$ & $20.21 \pm 0.203$ \\
Smoking & & & \\
Current smokers & & & \\
Ex-smokers & $26.28 \pm 0180$ & $24.00 \pm 0.174$ & $21.15 \pm 0.255^{2}$ \\
Never & $26.03 \pm 0.207$ & $24.22 \pm 0.200$ & $19.90 \pm 0.259$ \\
& $26.03 \pm 0.165$ & $23.89 \pm 0.160$ & $19.91 \pm 0.206$ \\
\hline
\end{tabular}

Scores adjusted for gender and age group.

${ }^{1} p<0.001$ vs. current drinkers and never drinkers.

${ }^{2} p<0.001$ vs. ex-smokers and never smokers.

TABLE 5. The asocciation between MHLC score and Body Mass Index

\begin{tabular}{lccc}
\hline & \multicolumn{3}{c}{ Mean \pm S.E. } \\
\cline { 2 - 4 } & $\begin{array}{c}\text { IHLC } \\
\text { (Internal) }\end{array}$ & $\begin{array}{c}\text { PHLC } \\
\text { (Powerful others) }\end{array}$ & $\begin{array}{c}\text { CHLC } \\
\text { (chance) }\end{array}$ \\
\hline Body mass index & & \\
$\geqq 25 \mathrm{~kg} / \mathrm{m}^{2}$ & $25.80 \pm 0.200^{1}$ & $23.44 \pm 0.192^{2}$ & $20.38 \pm 0.246^{3}$ \\
$18.5 \mathrm{~kg} / \mathrm{m}^{2}-25 \mathrm{~kg} / \mathrm{m}^{2}$ & $25.79 \pm 0.166^{1}$ & $23.41 \pm 0.160^{2}$ & $20.02 \pm 0.204^{3}$ \\
$<18.5 \mathrm{~kg} / \mathrm{m}^{2}$ & $25.75 \pm 0.360^{1}$ & $23.45 \pm 0.346^{2}$ & $20.69 \pm 0.442^{3}$ \\
\hline
\end{tabular}

Scores adjusted for gender, age group, occupational background, educational background, drinking status, and smoking status.

${ }^{1} p=0.991,{ }^{2} p=0.979,{ }^{3} p=0.083$ Results of ANOVA.

workers and $33.3 \%$ of women were farmers. Subjects who had graduated fom junior high school accounted for $57.5 \%$ of men and $51.8 \%$ of women. Concerning the health related behavior, $71.9 \%$ of men and $22.3 \%$ of women were current drinkers, and $53.1 \%$ of men and $8.9 \%$ of women were current smokers. Of the subjects aged under 70 years, $82.9 \%$ of men and $77.7 \%$ of women had a BMI of $18.5-25 \mathrm{~kg} / \mathrm{m}^{2}$. Subjects who regularly exercised more than 1 hour per week accounted for $29.6 \%$ of men and $33.2 \%$ of women.

Cronbach $\alpha$ was 0.69 for IHLC, 0.76 for PHLC, and 0.62 for CHLC. Table 2 shows the mean MHLC score across age groups. In all sub- scales, the mean scores increased with age $(p<0.001)$. As shown in Table 3 , after adjusting for age, the mean IHLC score tended to be higher for men, but both PHLC and CHLC were significantly higher for women, suggesting that women believe in more external control of one's own health than men. Table 3 also shows that there were significant differences in MHLC scores across educational/occupational backgrounds. After multiple comparison, farmers and self-employed workers showed significantly higher CHLC scores than office workers. Those who had completed only junior high school education showed higher PHLC and CHLC scores, indicat- 
TABLE 6. The association between MHLC score and exercise

\begin{tabular}{lccc}
\hline & \multicolumn{3}{c}{ Mean \pm S.E. } \\
\cline { 2 - 4 } & $\begin{array}{c}\text { IHLC } \\
\text { (Internal) }\end{array}$ & $\begin{array}{c}\text { PHLC } \\
\text { (Powerful others) }\end{array}$ & $\begin{array}{c}\text { CHLC } \\
\text { (Chance) }\end{array}$ \\
\hline Exercise habit & & & \\
More than 5 hours/week & $27.49 \pm 0.534$ & $24.03 \pm 0.532$ & $20.59 \pm 0.656$ \\
3-4 hours/week & $27.64 \pm 0.516$ & $24.06 \pm 0.514$ & $20.00 \pm 0.634$ \\
1-2 hours/week & $26.88 \pm 0.409$ & $23.95 \pm 0.408$ & $20.18 \pm 0.502$ \\
No exercise & $25.98 \pm 0.344^{\mathrm{a}}$ & $23.31 \pm 0.343$ & $20.58 \pm 0.423$ \\
\hline
\end{tabular}

Scores adjusted foer gender, age group, occupational background.

a $p<0.001$.

ing more external control belief.

The association between MHLC scores and health-related behavior is shown in Tables 4, 5, and 6 . There were significant cross-status differences in MHLC scores for drinking, smoking, and exercise. Subjects with adverse health-related behavior showed higher "external" scores. The results of multiple comparison showed that exdrinkers had higher scores for PHLC and CHLC than drinkers and never-drinkers. The CHLC score for current smokers was significantly higher than that for ex-smokers and never-smokers (Table 4). No significant relationship was found between body mass index and MHLC (Table 5). The results of multiple comparison showed that subjects who did not exercise had significantly lower IHLC scores than those who exercised 1-2 hours per week or more (Table 6).

\section{Discussion}

Reliability of the MHLC scale

We examined the internal consistency of the MHLC scale in order to assess its reliability. The range of Cronbach $\alpha$ in the present study was 0.62-0.76 which was comparable to that in Wallston's normative data (0.67-0.77) and thus sufficiently adequate for administration to Japanese adults.

\section{Cross-validity of the MHLC scale}

We carried out a cross-cultural comparison between the present results and previous reports from Western countries. In the present study, higher age groups showed higher mean MHLC scores in all subscales. PHLC and CHLC scores were higher for women than for men. Subjects who had completed only junior high school education showed significantly high PHLC and CHLC scores.

The association between less education and higher "external" belief is consistent with Western reports including the normative data of Wallston and Wallston (1981) and the report of Gallanos et al. (1994). Their data indicated that individual with less than 12 years of education had significantly higher PHLC and CHLC scores than those with 12 years of education or more, which was also consistent with the present results.

While Wallston and Wallston's normative data (1981) indicated no significant difference between men and women, our data showed higher PHLC and CHLC scores for women. This does not conflict with previous studies, including that of Wrightson and Wardle (1997), which showed that Asian women had higher "external" belief than Caucasian women. In their study, South Asian women scored higher on PHLC and CHLC than European or Afro-Caribbean women, perhaps reflecting cultural influences.

Our results indicated that MHLC scores were correlated with health-related behavior in the Japanese population, and were also consistent with the general Western norm that people exhibiting beneficial health-related behavior such as 
exercise have more "internal" belief, whereas those with adverse health-related behavior, such as smoking and excess drinking, have more "external" belief. Ozasa et al. (1995) investigated the relationship between various indices including HLC and health-related behavior such as smoking, drinking, diet, and exercise habits in a Japanese community setting. Because they used their own questionnaire, which included part of the MHLC, we cannot cross-validate their findings with ours. However, their results indicated that elderly male ex-drinkers had low "internality", consistent with our present finding, suggesting that HLC has a consistent association with health-related behavior in Japanese subjects.

The external validity of the present findings is an important issue. The subjects of the present study were National Health Insurance beneficiaries living in rural Japan, and this must be considered when attempting to generalize our results to other populations. Notwithstanding this limitation, however, this is the first study to have examined the reliability and validity of the MHLC scale in a Japanese community setting with a large sample size.

In our study, the MHLC scale showed reasonably adequate alpha reliability. In addition, our results suggested that the MHLC could distinguish Japanese subjects according to demographic factors or health-related behavior. Thus, use of the MHLC scale should help to provide a better understanding of Japanese health belief and could be beneficial for developing effective health education programs. Further study should be encouraged to confirm consistency regarding the validity of the MHLC scale, targeting other Japanese populations such as those at particular work sites.

\section{Acknowledgments}

Funding for this study was supported by a Health Science Research Grant from the Health Service, Ministry of Health and Welfare, Japan.

\section{References}

Bennett, P., Norman, P., Moore, L., Murphy, S. \& Tudor-Smith, C. (1997) Health locus of control and value for health in smokers and non smokers. Health Psychology, 16, 179-182.

Calnan, M. (1989) Control over health and patterns of health related behavior. Soc.Sci. Med., 29, 131-136.

Fleming, M.F. \& Barry, K.L. (1991) Health locus of control in a primary care sample of alcoholics and nonalcoholics. Behav. Med., 17, 25-30.

Gallanos, A., Strauss, R.P. \& Pieper, C. (1994) Sociodemographic correlates of health beliefs among black and white community dwelling elderly individuals. Int. J. Aging and Human Development, 38, 339-350.

Horige, Y. (1991) Japanese version of the health locus of control scales. Kenko Shinrigaku Kenkyu, $\mathbf{4}$, 1-7. (in Japanese)

Murphy, G.C., Foreman, P.E., Simpson, C.A., Simpson, C.A., Molloy, G.N. \& Molloy, E.K. (1999) The development of a locus of control measure predictive of injured athletes' adherence to treatment. Journal of Science and Medicine in Sport, 2, 145-152.

Ozasa, K., Higashi, A., Watanabe, Y., Shimouchi, A., Hayashi, K., Hatta, H., Morita, M., Fukumoto, M., Masumoto, T., Oonishi, T., Oonishi, S., Fukuma, K., Fujita, K., Asada, K., Yuge, M. \& Kawai, K. (1995) Characteristics of smoking, drinking, dietary habits, and physical exercise in health behavioral modes. Jpn. J. Public Health, 42, 1029-1041.

Parcel, G.S. \& Meyer, M.P. (1978) Development of an instrument to measure children's health locus of control. Health Educ. Monogr., 6, 149-159.

Paxton, S. \& Sculthorpe, A. (1999) Weight and health locus of control beliefs in an Australian community sample. Phsycol. Health, 14, 417-431.

Pitts, M. (1991) An introduction to health psychology. In: The Psychology of Health, edited by M. Pitts and K. Phillips, Chapman and Hall Inc., New York, pp. 3-14.

SAS Institute (1992) SAS/STAT manual release 6.07. SAS Institute Inc, Cary, NC, USA.

Schank, M.J. \& Lawrence, D.M. (1993) Young adult women: lifestyle and health locus of control. $J$. Adv. Nur., 18, 1235-1241.

Slenker, S.E., Price, J.H. \& O'Connell, J.K. (1985) Health locus of control of joggers and nonexercisers. Percept Mot Skills, 61, 323-328. 
Stuart, K., Borland, R. \& McMurray, N. (1994) Selfefficacy, health locus of control, and smoking cessation. Addict. Behav., 19, 1-12.

Tsuji, I., Nishino, Y., Ohkubo, T., Kuwahara, A., Ogawa, K., Watanabe, Y., Tsubono, Y., Bando, T., Kanemura, S., Izumi, Y., Sasaki, A., Fukao, A., Nishikori, M. \& Hisamichi, S. (1998) A prospective cohort study on national health insurance beneficiaries in Ohsaki, Miyagi prefecture, Japan: Study design,profiles of the subjects and Medical cost during the first year. J. Epidemiol., 8, 258-263.

Wallston, K.A. \& Wallston, B.S. (1978) Development of the multidimensional health locus of control (MHLC) scales. Health Educ. Monogr., 6, 160-170.
Wallston, K.A. \& Wallston, B.S. (1981) Health locus of control scales. In : Research with the Locus of Control Construct, edited by Lefcourt HF, Academic Press, New York, pp. 189-243.

Wallston, K.A. \& Wallston, B.S. (1982) Who is responsible for your health? The construct of health locus of control. In : Social Psychology and Illness, edited by G. Sanders \& J. Suls, Erlbaum Hillsdale, NJ, pp. 65-95.

Wallston, K. (1989) Assessment of control in health care setting. In : Stress, Personal Control and Health, edited by A. Steptoe \& A. Appels, John Wiley \& Sons Ltd.,West Sussex, pp. 85-106.

Wrightson, K.J. \& Wardle, J. (1997) Cultural variation in health locus of control. Ethn. Health, 2, $13-20$. 